\title{
AUTOESTIMA E ALFABETIZAÇÃO: O QUE HÁ NESSA RELAÇÃO?
}

\author{
CLARICE SALETE TRAVERSINI \\ Professora do Departamento de Ensino e Currículo, da Faculdade \\ de Educação da Universidade Federal do Rio Grande do Sul \\ clarice.traversini@ufrgs.br
}

\begin{abstract}
RESUMO
Este artigo tem como objetivo analisar um conjunto de práticas utilizadas para alfabetizar jovens e adultos, as quais têm no resgate da autoestima seu foco central. O estudo utilizou uma parcela dos discursos do Programa Alfabetização Solidária registrados em um conjunto de publicações periódicas editadas entre 1997 e 2002, cuja circulação tinha abrangência nacional. Inspirada nos estudos de Michel Foucault, a análise contou com as noções de governamento e discurso. O argumento desenvolvido no texto pretende mostrar que a ênfase na elevação da autoestima funciona como uma das estratégias de governamento do Programa Alfabetização Solidária. As estratégias são operacionalizadas por meio: da produção da baixa autoestima como um problema para efetivar o processo de alfabetização; do desenvolvimento da autoconfiança pelo disciplinamento de corpos e mentes; e da produtividade da estratégia de valorização da autoestima evidenciada na mudança de conduta dos alfabetizandos. Essas práticas investem na elevação da autoestima e da estima aos outros, apostando no envolvimento, na persistência e na permanência do aluno nos programas de alfabetização para operar as mudanças desejadas nos indivíduos e nos locais com elevados índices de analfabetismo.

AUTOESTIMA - ALFABETIZAÇÃO DE JOVENS E ADULTOS - PROGRAMA ALFABETIZAÇÃO SOLIDÁRIA
\end{abstract}

\section{ABSTRACT}

SELF-ESTEEM AND LITERACY: WHAT MAY BE IN THIS RELATIONSHIP? This paper aims at analyzing a group of practices that have been used to alphabetize youths and adults, which have the recovery of self-esteem as their central focus. This study has employed part of discourses of the Solidary Literacy Program (Programa Alfabetização Solidária), recorded in a series of periodical publications, from 1997 to 2002, which were nationally distributed. From studies carried out by Michel Foucault, this analysis has considered the notions of government and discourse. The argument developed in this text intends to show that the emphasis on raising self-esteem has functioned as one of the governing strategies of the Solidary Literacy Program. The strategies have been brought into operation by means of production of low self-esteem as a problem that hinders the literacy process; development of self-confidence by disciplining bodies and minds; and productivity of the strategy of valuing self-esteem evidenced in the change of conduct of individuals who become literate. These practices invest in raising one's own self-esteem as well as the others', 
betting on the involvement, persistence and permanence of the student in literacy programs to operate the desired changes both in the individuals and in the places with high illiteracy indexes. SELF-ESTEEM - ADULT EDUCATION - LITERACY - PROGRAMA ALFABETIZAÇÃO SOLIDÁRIA

Os analfabetos foram (e continuam sendo) narrados como indivíduos pouco produtivos, explorados, excluídos da sociedade, que se sentem envergonhados pela sua condição. $\bigcirc$ sentimento de vergonha por não saber ler e escrever explicita-se ainda mais quando o analfabeto precisa assinar documentos com o polegar ou depende do auxílio de outras pessoas para identificar a rota de ônibus, reconhecer preços de produtos, ler documentos oficiais e escrever cartas aos seus parentes e amigos distantes.

A necessidade de mudar tais características atribuídas aos analfabetos é recorrentemente encontrada como justificativa para a realização de programas de alfabetização de jovens e adultos. Uma das ações amplamente anunciadas para alcançar a prometida mudança centra-se no resgate da autoestima. Se prestarmos atenção não apenas nos programas de alfabetização de jovens e adultos, mas também em outras propostas derivadas de políticas educacionais inclusivas, encontraremos o resgate da autoestima como um investimento para atingir as metas desejadas.

Estudos sobre a autoestima aumentaram nas últimas décadas e fazem parte do interesse de pesquisadores de diferentes áreas. Apenas como exemplo, consultando o banco de teses disponibilizado pelo site da Coordenação de Aperfeiçoamento de Pessoas de Nível Superior - Capes' -, partindo-se da palavra-chave "autoestima", encontram-se registros de 54 I teses e dissertações tematizando de alguma forma o assunto. Se ampliarmos a busca, considerando os estudos sobre autoajuda ou literatura de autoajuda como tema relacionado, incluem-se 63 pesquisas. Somadas, ultrapassam 600 investigações, o que evidencia o interesse por parte da comunidade acadêmica no estudo dessas temáticas.

Centrei atenção no termo, em seus usos e nos significados a ele atribuídos porque compartilho da perspectiva de que somos seres produzidos pela linguagem e de que o modo como nos narramos ou somos narrados é uma das condições para nos construirmos como sujeitos. Assim, o presente artigo é

I. Disponível em www.capes.gov.br/capes/portal/conteudo/I0/Banco_Teses.htm; acesso em 10 fev. 2007. 
efeito da inquietação expressada no título e tem como objetivo problematizar o resgate da autoestima, discurso corrente na educação e, particularmente, nos processos de alfabetização de jovens e adultos.

Esse discurso adquiriu tal caráter de verdade e aceitabilidade no processo educativo que é difícil perceber o que se pode questionar nele. Para operacionalizar a problematização, estudei um dos programas vigentes na última década no país, o Programa Alfabetização Solidária², procurando identificar e analisar um conjunto de práticas utilizadas para alcançar o aumento da alfabetização que têm no resgate da autoestima seu foco central.

Para realizar o objetivo proposto, busquei perspectivas teóricas que auxiliassem a questionar o discurso da autoestima. Contei com os estudos de Michel Foucault, especialmente com a noção de "governamento". Antes de continuar, é preciso esclarecer que o termo "governamento" é utilizado aqui diferenciado de "governo", como propõe Veiga-Neto (2002). O primeiro termo, "governamento", refere-se à direção da conduta de si e dos outros, recorrente nas produções de Foucault, enquanto o segundo, "governo", é usado para indicar uma instância centralizada na esfera federal, estadual ou municipal, de caráter administrativo.

Em suas análises sobre como nos tornamos os sujeitos que somos, em particular nas sociedades ocidentais, o filósofo Michel Foucault leva em conta não apenas o modo como os outros dirigem nossas condutas, o que ele denomina de "técnicas de dominação", mas também as "técnicas do eu", ou seja, os processos de ação do individuo sobre si próprio. "O ponto de contato do modo como os indivíduos são manipulados e conhecidos por outros encontrase ligado ao modo como se conduzem e se conhecem a si próprios. Pode chamar-se a isto o governo [governamento]" (Foucault, 1993, p.208). Nesse sentido, governar as pessoas não é uma forma de submetê-las para que façam o que quer o dirigente (ou quem está na posição de comando). "É sempre um difícil e versátil equilíbrio de complementaridade e conflito entre técnicas que asseguram a coerção e processos por meio dos quais o eu é construído e modificado por si próprio" (Foucault, 1993, p.208).

2. Até 2002, o Programa Alfabetização Solidária utilizava a sigla PAS; após essa data, passou a ser apresentado com o mesmo nome, mas mudando a sigla para Alfasol. Talvez a mudança seja devida ao final do mandato do Presidente no qual o programa foi criado. 
Para governar, há necessidade do uso de estratégias, compreendidas por Foucault (1995) em três sentidos: primeiro, "a escolha dos meios empregados para se chegar a um fim"; segundo, "a maneira pela qual um parceiro, num jogo dado, age em função daquilo que ele pensa dever ser a ação dos outros, e daquilo que ele acredita que os outros pensarão ser a dele"; e, terceiro, "o conjunto dos procedimentos utilizados num confronto para privar o adversário dos seus meios de combate e reduzi-lo a renunciar à luta" (p.247). A estratégia passa a ser definida como a "escolha de soluções 'vencedoras'" (p.248).

Como material empírico para a investigação, selecionei uma parcela dos discursos do Programa Alfabetização Solidária. Criado em 1997 pelo Conselho da Comunidade Solidária, na gestão do Presidente da República Fernando Henrique Cardoso, o Programa traçou como principal meta a erradicação do analfabetismo no Brasil. Municípios do Norte e Nordeste são prioritários no atendimento e escolhidos de acordo com índices de analfabetismo registrados no censo do Instituto Brasileiro de Geografia e Estatística - IBGE. Atua também nas regiões metropolitanas do Distrito Federal, São Paulo, Rio de Janeiro, Belo Horizonte, Goiânia, Fortaleza e São Luís, que concentram "um número absoluto elevado de pessoas que não sabem ler e escrever" (Alfabetização Solidária, 2007). Desde 1998, o gerenciamento do Programa está sob a responsabilidade da Associação dos Amigos do Programa Alfabetização Solidária - APAS -, que define a si própria como uma organização não governamental, sem fins lucrativos e de utilidade pública.

O Programa funciona por meio das seguintes parcerias: as pessoas físicas ou os voluntários financiam a alfabetização dos alunos nos grandes centros urbanos; as empresas, organizações e instituições financiam a alfabetização de alunos nos municípios com elevados índices de analfabetismo; as instituições de ensino superior são responsáveis pela execução do projeto pedagógico, incluindo "aperfeiçoamento dos alfabetizadores"; e as prefeituras oferecem os espaços físicos para funcionamento das salas de aula.

De 1997 a 2002, as empresas privadas, os voluntários e algumas instituições governamentais dividiam o custo-aluno equitativamente com o MEC. Cada um doava $R \$ 17,00$ por mês por aluno durante seis meses (Boletim Alfabetização Solidária, 1997). Atualmente, as publicações do Programa não mencionam mais o MEC como parceiro. No site, há informação de que o custo-aluno é dividido entre os parceiros, sem se fazer referência ao órgão governamental. 
O valor doado pelos parceiros é de $\mathrm{R} \$ 21$ 1,00/mês por aluno no período de seis meses, aplicado em material didático e pedagógico, formação de bibliotecas e pagamento de bolsa ao alfabetizador (Alfabetização Solidária, 2007).

A parcela dos discursos analisados foi extraída de um conjunto de materiais produzidos pelo Programa, dentre os quais, foram selecionadas publicações periódicas - no período de 1997 até 2002, momento de término da coleta de dados -, editadas de forma sistemática e dirigidas aos diferentes parceiros do Programa. Para a produção deste artigo, foram analisadas as publicações que faziam referência ao resgate da autoestima. Foram, então, selecionadas as seguintes publicações: nove edições do Boletim Alfabetização Solidária ${ }^{3}$, uma edição da Revista do Programa Alfabetização Solidária, uma edição dos registros dos vencedores do Concurso de Redação e três edições dos Relatórios de Atividades do Programa.

No caminho investigativo, fiz a opção pela análise de discurso de inspiração foucaultiana. Segundo Fischer (200I , 2002), esse processo implica considerar o corpus de pesquisa como um conjunto de textos produzidos por meio de práticas sociais. E mais, é preciso "analisá-los igualmente como práticas que são, como constituidores de sujeitos e corpos, de modos de existência não só de pessoas, como de instituições e inclusive de formações sociais mais amplas" (Fischer, 2002, p.43). Procurei olhar para as informações contidas nas publicações

...não como realidades mudas, as quais, por um trabalho de interpretação e análise, seriam despertas, revelando sentidos escondidos, palavras talvez nunca faladas, as quais seriam orientadas por uma certa iluminação teórica definidora do que realmente diriam os ditos. Os textos seriam vistos na sua materialidade pura e simples de coisas ditas em determinado tempo e lugar. (Fischer, 2002, p.43-44)

Na sua aula inaugural denominada "A ordem do discurso", proferida no Collège de France em 2 de dezembro de 1970, Foucault mostra que as práticas discursivas são atravessadas por poderes, e evidencia que, em nossas

3. Até a $16^{\text {a }}$ edição, a revista chamava-se Boletim Alfabetização Solidária; depois, passou a denominar-se Escrevendo Juntos. 
sociedades, existem diversos procedimentos que controlam, selecionam e organizam a produção dos discursos. Para ele, a história nos mostra que "o discurso não é simplesmente aquilo que traduz as lutas ou sistemas de dominação, mas aquilo por que, pelo que se luta, o poder do qual nos queremos apoderar" (Foucault, 1998, pl0).

Partindo dessa perspectiva, identifiquei e li os textos contidos nas publicações selecionadas, prestando atenção nas recorrências das informações, aquelas que convergiam para fortalecer o discurso da autoestima como condição para o aluno se alfabetizar. Ao conjunto de recorrências encontradas, chamei de unidades de estudo, não com o objetivo de fixar-lhes o sentido, e, sim, de problematizá-las, para mostrar como é possível governar, isto é, conduzir as ações dos alfabetizandos e alfabetizadores por meio de estratégias que fortalecem sua autoestima.

Após esse breve delineamento dos caminhos percorridos para realizar a pesquisa, argumento, neste texto, que a ênfase na elevação da autoestima funciona como uma das estratégias de governamento do Programa Alfabetização Solidária. Um conjunto de práticas que investem na elevação da estima aos outros e na autoestima é colocada em ação, apostando no envolvimento, persistência e permanência do aluno no Programa para operar as mudanças desejadas nos indivíduos e nos locais com elevados índices de analfabetismo.

A seguir, explicito esse argumento em três seções: a primeira refere-se a alguns enunciados que produzem a baixa autoestima como um problema para efetivar o processo de alfabetização; a segunda mostra um conjunto de ações importantes para adquirir autoconfiança: disciplinar corpos e mentes; e a terceira enfoca a produtividade da estratégia da autoestima na conduta dos indivíduos.

\section{A BAIXA AUTOESTIMA COMO UM OBSTÁCULO PARA O PROCESSO DE ALFABETIZAÇÃO}

Resgatar a autoestima é uma tarefa considerada importante no processo de erradicação do analfabetismo. Nos textos publicados pelo Programa, registra-se que, durante algumas atividades realizadas com os alunos nos cursos de alfabetização, eles "demonstraram um enorme sentimento de opressão". Segundo esses registros, "a opressão que sentiam estava vinculada ao anal- 
fabetismo" (André, Godoy, 200 I, p. I I). Em outra publicação, reitera-se que o analfabetismo produz no indivíduo "um sentimento de inferioridade, de vergonha de si mesmo" (Boletim Alfabetização Solidária, 1999b, p.7). O sentimento de opressão e de inferioridade, a vergonha, o estigma por não saber ler e escrever e o temor do preconceito são condições geradoras de baixa autoestima. Isso constitui um problema para o desenvolvimento do Programa, visto que pode dificultar o processo de alfabetização.

O pressuposto de que a autoestima facilita o processo de aprendizagem expande-se com as pedagogias de base psicológica. No processo de alfabetização, observa-se, no Brasil, desde a década de 80, o fortalecimento da relação entre autoestima e aprendizagem com as pedagogias construtivistas. Enfatizase o sucesso dessa relação nos processos de alfabetização ou escolarização das chamadas crianças em situação de fracasso escolar ou com dificuldades de aprendizagem.

Quanto à alfabetização de jovens e adultos, a relação entre autoestima e aprendizagem pode ter se fortalecido com a difusão das práticas pedagógicas consideradas emancipatórias. A alfabetização partindo da realidade do aluno, a leitura e a escrita como processos de conscientização dos indivíduos oprimidos para livrá-los da opressão dos dominantes, as práticas pedagógicas apostando no aluno e no alfabetizador como agentes de transformação da realidade, a crítica à separação entre "seriedade docente" e "afetividade" são algumas dessas práticas. Elas propagam a relação entre autoestima e aprendizagem dos alfabetizandos adultos para evitar o fracasso do processo de alfabetização.

Ressalto não ser meu propósito, neste artigo, comprovar se as práticas emancipatórias perderam seu vigor ou não atingiram suas metas. O objetivo é mais modesto: chamar a atenção para as propostas educacionais consideradas alternativas às propostas oficiais, tidas como emancipatórias e democráticas, pelas quais tanto lutamos nas últimas três décadas, que foram adquirindo diferentes sentidos e usos, como nos mostra Corazza (200I). Parece que a mesma linguagem construída com o objetivo de tornar o sujeito comprometido com as questões sociais de seu tempo acabaram sendo úteis também para produzir o sujeito individualista almejado pela lógica da competitividade e do consumo da contemporaneidade.

Continuando a análise dos discursos do PAS, observa-se que a autoestima é considerada como "o segredo que assegura a efetivação do trabalho 
de alfabetização", visto ser a "promotora do desenvolvimento na relação do sujeito e objeto" (Boletim Alfabetização Solidária, 1998b, p.3). O Programa aposta nisso, pois, quando o analfabeto ingressa no curso de alfabetização e inicia a aprendizagem da leitura e da escrita, passa a "se gostar, se respeitar e se valorizar" e, aos poucos, vai resgatando sua autoestima. Assim, esta constitui um "elemento de conquista, tanto do alfabetizador quanto do alfabetizado" (Boletim Alfabetização Solidária, 1998a, p.3). Ambos precisam resgatar sua autoestima para o sucesso da alfabetização.

No Programa, a autoestima é, ao mesmo tempo, uma estratégia para a alfabetização eficiente e uma promessa aos alfabetizadores. Com o Programa, além das metas de erradicação do analfabetismo, de promoção da educação de jovens e adultos e de incentivo à requalificação profissional nos municípios envolvidos, propõe-se o aumento da cidadania, da prosperidade individual e social, da autorrealização e da autoestima. A autoestima, em particular, consiste em uma importante estratégia utilizada com o intuito de facilitar a aprendizagem dos alunos, que, uma vez alfabetizados, tenderiam a melhorar suas vidas, alcançando felicidade, autonomia e inclusão social.

É preciso levar em conta que a linguagem narra realidades de acordo com as verdades instituídas em determinados momentos históricos. As verdades validadas, revalidadas e invalidadas no decorrer dos tempos constroem objetos e realidades normais ou problemáticas. Por meio da linguagem, a baixa autoestima é tratada como um problema, ou seja, descreve-se como se manifesta no indivíduo e os malefícios nele produzidos. Esse procedimento propicia traduzir a autoestima como algo problemático: uma interferência substantiva tanto na aprendizagem da leitura e escrita quanto no autoconceito que o indivíduo tem de si. Esse processo configura a autoestima como um campo fértil para intervenção, ou melhor, gera as condições necessárias para fabricar instrumentos e nela intervir.

\section{ADQUIRIR AUTOCONFIANÇA DISCIPLINANDO CORPOS E MENTES}

Para alcançarem a meta de se alfabetiza, resgatar sua autoestima, mudar o autoconceito negativo e sentir-se independentes, os analfabetos precisam, entre outras ações, disciplinar seus corpos e mentes. As aulas de alfabetização ocorrem geralmente à noite, após a jornada de trabalho, o que exige "persistência", 
"empenho", abdicação das horas de descanso para aprender a ler e escrever. Nas publicações do PAS, estão registradas várias das dificuldades enfrentadas pelos alunos para se alfabetizarem: "os irmãos Carlos [...] e José Domingos [...], trabalham duro todos os dias. $\bigcirc$ primeiro, numa olaria, o outro, na agricultura. À noite se encontram na sala de aula" (Programa Alfabetização Solidária, 200 I , p. I I). Outro relato informa que, "após 9 horas de trabalhos diários na lavoura, [os alfabetizandos] caminham quilômetros para chegar às salas de aula do Programa Alfabetização Solidária. O objetivo é um só: aprender" (Boletim Alfabetização Solidária, 1999a, p.5). Ainda outro aluno mostra "as mãos calejadas" a uma representante da Diretoria de Cooperação Internacional do Ministério das Relações Estrangeiras da França, quando ela visitou uma das salas do Programa no município pernambucano de Panelas. O alfabetizando declarou-lhe: "Eu passo o dia todo trabalhando e ainda encontro ânimo para assistir às aulas, isso é muito importante para mim" (Klein et al., 2000, p. 19).

Uma das hipóteses levantadas, a partir da leitura dessas informações, é a de que os alfabetizandos são narrados como pessoas com tanta vontade de aprender que dominam o cansaço do trabalho diário para atingir esse objetivo. A vontade de aprender seria uma condição para elevar sua autoestima, mobilizando-os não apenas a permanecer na sala de aula para se alfabetizar, como também construindo uma representação deles próprios como "bons alunos" para si e para os outros: professores, coordenadores e visitantes, como é a situação descrita. Tavares (2002) evidencia em sua pesquisa que a imagem dos professores sobre os alunos com elevada autoestima está vinculada com a representação já existente de bom aluno. Além disso, a pesquisadora apresenta outra instigante constatação: os professores investigados apropriaram-se do conceito de autoestima tendo como base a literatura de autoajuda.

A busca por mostrar a necessidade de disciplinar o corpo e a mente como condições para persistir na luta individual contra o analfabetismo pode ser exemplificada em uma das publicações, na seção intitulada "Perfil do aluno do Alfabetização Solidária". Nela, destaca-se que "o cansaço, muitas vezes, é o maior inimigo para o sucesso do processo de aprendizagem" (Programa Alfabetização Solidária, 2000a, p. I 4). Em detalhes, a seção descreve as condições geradoras do cansaço: a primeira é o trabalho duro na agricultura e nas fábricas. A segunda é a jornada de trabalho acima de oito horas diárias. A terceira são 
as longas distâncias percorridas a pé, da casa ao trabalho e, posteriormente, da casa para as salas de aula. E, por fim, há o acúmulo de atividades desenvolvidas para sustentar a família.

O esforço físico despendido no trabalho diário tratado como algo que dificulta a aprendizagem não é uma preocupação surgida com o Programa Alfabetização Solidária. Vários projetos de alfabetização e de escolarização noturna para jovens e adultos, desenvolvidos após uma jornada de trabalho, têm-se deparado com o cansaço físico dos alunos como algo que provoca evasão, baixa aprendizagem e reprovação de muitos deles.

Pesquisas como a de Silva (2003), acerca das representações sociais da escola noturna, mostram que estudar à noite é uma possibilidade de o aluno provar sua capacidade e de elevar seu nível de escolarização, mesmo após um cansativo dia de trabalho. Persiste a noção da escola noturna como uma instituição de suplência e de caráter reparador do direito à educação, muitas vezes não usufruído, bem como do conhecimento não adquirido no tempo previsto. No entanto, a vivência dos alunos no cotidiano escolar e a imagem produzida socialmente fortalecem a ideia da escola noturna como uma opção de ensino para aqueles sujeitos com problemas de aprendizagem que interferiram no percurso escolar a ser trilhado.

A fim de evitar que o esforço físico diário desmobilize o aluno para frequentar as aulas, a autoestima adquire um potencial estratégico no Programa: maximiza o desejo de ler e escrever e incide sobre a ação dos alfabetizandos para que eles mesmos se disciplinem para persistir nas aulas e se tornem alfabetizados. Para isso, exige-se, por um lado, "força de vontade" e "esforço" dos alfabetizandos, vencendo o cansaço e as dificuldades cotidianas. Por outro lado, é preciso que eles estejam "motivados para a alfabetização" (Boletim Alfabetização Solidária, 1998a, p. 3).

Isso requer dos alfabetizadores planejamentos e proposição de atividades vinculando os conhecimentos a serem aprendidos com os interesses dos alfabetizandos. É como se a autoestima fizesse parte da vida do sujeito em algum momento em que frequentou a escola, antes de "evadir-se", e agora precisa ser resgatada. $\bigcirc$ resgate da autoestima, então, é realizado mediante o exercício da autodisciplina dos próprios alfabetizandos e por intermédio das ações propostas pelos alfabetizadores. A ênfase na valorização da autoestima consiste em uma forma de intervenção para agir sobre o problema individual 
do analfabetismo.

A preocupação do Programa com o resgate da autoestima, da autorrealização e da autoconfiança assemelha-se aos discursos de autoajuda que circulam amplamente no mundo contemporâneo e nos prometem alegria, felicidade, prazer e realização pessoal. Rudiger ( 1996) realizou estudos analisando como se estrutura a categoria indivíduo na literatura da autoajuda e de que maneira seus discursos se articulam na constituição da subjetividade contemporânea.

O autor considera que "a literatura de autoajuda é expressão textual de um conjunto de práticas engendrado pela cultura popular anglo-saxã, que se transplantou para toda a parte" (Rudiger, 1996, p. I I). Trata-se de práticas por meio das quais "as pessoas procuram descobrir, cultivar e empregar seus supostos recursos interiores e transformar sua subjetividade" (p. I I). Com sentido variado e diversos campos de aplicação, o autor destaca que a literatura de autoajuda tem como base "o princípio de que possuímos um poder interior, passível de ser empregado na solução de todos os nossos problemas" (p. I7). Rudiger destaca ainda que tudo se passa como se "os problemas com que [o indivíduo] luta, embora se originem de fatores sociais, possuem uma natureza pessoal, que não tem nada a ver com a sociedade" (p. 17).

Mas o que há em comum entre os discursos do Programa Alfabetização Solidária e os de autoajuda? Inspirada em Rudiger ( 1996) e Silva (200 I), posso dizer que, em ambos os discursos, se encontram mecanismos de intervenção, produzindo-nos como determinados tipos de pessoas - no caso em estudo, como alfabetizados. Nesse sentido, o processo de alfabetização consiste em uma forma de intervenção para governar a subjetividade. A vida dos analfabetos, dos alfabetizandos, dos alfabetizadores, enfim, de todos nós que trabalhamos com educação, está permanentemente enredada em relações de poder que nos subjetivam e nos governam.

Ao se transformarem os analfabetos em indivíduos livres do analfabetismo, da vergonha, dos sentimentos de opressão e de inferioridade, tal liberdade não deixará de ser conduzida, regulada e administrada. No momento em que se incita cada alfabetizando a se tornar um sujeito autorrealizado, autônomo, alguém disposto a aprender continuamente e com capacidade de resolver problemas, conduz-se o indivíduo a ser um determinado tipo de pessoa considerada útil pela e para a racionalidade neoliberal que rege nossas sociedades 
contemporâneas.

Nessa racionalidade, são engendrados mecanismos para potencializar os aspectos subjetivos dos indivíduos, para desenvolver as capacidades de escolha dos consumidores, para governar a "alma do cidadão" (Rose, I998, p.3 I). A educação, a pedagogia e os próprios programas de alfabetização estão envolvidos na constituição do tipo de sujeito almejado por essa racionalidade: cidadão, autônomo, autorrealizado, em contínuo processo de aprendizagem. No Brasil, a produção desse sujeito tem sido operacionalizada por uma variedade de programas e reformas educacionais na contemporaneidade, conforme têm mostrado Veiga-Neto (2000), Corazza (200I), Bujes (2002) e Klein (2003), entre outros pesquisadores.

\section{A PRODUTIVIDADE DA ESTRATÉGIA DA AUTOESTIMA NA CONDUTA DOS INDIVÍDUOS}

O termo "produtivo" é utilizado neste texto no sentido de mostrar alguns possíveis efeitos produzidos pelos discursos analisados sobre o modo como os alfabetizandos conduzem suas vidas e a de suas comunidades.

Em uma das publicações semestrais sobre a avaliação de um dos módulos do Programa Alfabetização Solidária, destacam-se algumas "conquistas pedagógicas" que a alfabetização propiciou aos indivíduos: "melhora significativa na comunicação, fluência e articulação" resultando em "maior clareza e sequência dos fatos na exposição de ideias" e "percepção da função social da escrita/leitura". A publicação menciona também que a leitura e a escrita geram "benefícios" na vida dos "cidadãos", tais como: "mobilização e empenho para a continuidade dos estudos; melhora da autoestima; valorização da sua cultura de origem e respeito e valorização à cultura dos demais" (Programa Alfabetização Solidária, 2000, p.3 I).

Já em um artigo elaborado por uma das coordenadoras universitárias do PAS, encontra-se um relato destacando outro efeito: a conexão do "letramento dos alunos com o da comunidade". Para efetivar essa ação, os alfabetizadores utilizaram cartazes confeccionados pelos próprios alunos. A coordenadora universitária do Programa cita que, "para os alfabetizandos, conseguir produzir e ler os cartazes, mesmo com a ajuda do professor, os fazia sentir mais próximos da comunidade escolarizada" (Terzi, 200 I, p. |48).

Ainda, numa reportagem de capa de um dos boletins bimestrais do 
Programa, destacando a premiação recebida da $\mathrm{ONU}$, ressalta-se a "formação do cidadão" como um dos efeitos atingidos pelo processo de alfabetização. No texto, afirma-se que, "ao aprender a ler e a escrever, os alunos passam a enxergar novos horizontes, melhoram a capacidade de expressão oral e de compreensão da realidade em que vivem". E complementa-se: "mais do que decodificar símbolos, desvendam um mundo até então desconhecido" (Boletim Alfabetização Solidária, 2000, p.5).

Os registros mostram o uso da aprendizagem da leitura e escrita como uma forma de modificar modos de vida, segundo os registros, trazendo melhoria no cotidiano do alfabetizando e da sua comunidade. É importante destacar que não estou lançando dúvidas se o Programa mudou ou não a vida de cada um e das comunidades para melhor, pois não é esse o objetivo do estudo. Chamo a atenção para outros sentidos encontrados nos registros, se atentarmos para os detalhes neles contidos. Um deles é a responsabilização do analfabeto pela sua condição de analfabetismo, como veremos seguir.

O investimento nas capacidades pessoais dos alfabetizadores e dos alfabetizandos para alfabetizar e provocar mudanças nos indivíduos e comunidades é "recompensado" quando a autoestima se torna um efeito do processo de alfabetização. Para os coordenadores universitários e os alfabetizadores, o resgate ou aumento da autoestima pode ser percebido por meio da "alegria de aprender a ler e a escrever" manifestada pelos alfabetizandos durante e após o curso de alfabetização (Boletim Alfabetização Solidária, 1997, capa).

Nas pesquisas realizadas para identificar "o aspecto psicológico e o reflexo dos estudos na vida dos alunos do Alfabetização Solidária”, as coordenadoras das universidades parceiras "perceberam um certo prazer e elevação da autoestima nos alunos" (Klein et al., 2000, p.2I). Outras vezes, nas publicações dirigidas aos parceiros, o Programa destaca: "ler e escrever torna a pessoa mais confiante e, acima de tudo, proporciona a integração à sociedade" (Boletim Alfabetização Solidária, 1999b, p.7).

Os próprios alfabetizandos expressam os efeitos produtivos da autoestima obtida no curso de alfabetização. Um deles é a eliminação da vergonha: "com a leitura consigo até convesa milhor com meus amigo sem medo de passa vergonha que me seguiu durante o tempo que eu era analfabeto. Hoje ganhei o maior troféu eu sou alfabetizado" [sic] (Programa Alfabetização Solidária, 2000a, p.5). O outro efeito expressado é a felicidade por conseguir 
emprego, conforme carta de um aluno do Programa Alfabetização Solidária do Município de Lagoa de Pedras (RN) para a professora alfabetizadora: "estou Ihe escrevendo para agradecer o curso que fiz do comunidade solidária. Pois para mim foi muito proveitoso. Fiz o curso de gari na Prefeitura e passei em segundo lugar. Só tenho que me sentir muito feliz pelo êxito alcançado" [sic] (Boletim Alfabetização Solidária, 1998, p.3).

Interessante ressaltar, ainda, que nas cartas há o reconhecimento aos alfabetizadores, agradecendo-se pela sua "paciência" com o alfabetizando: "gostaria de agradecer nossa professora por ter muita paciência com noz" [sic] (Boletim Alfabetização Solidária, 1999, p.3). Para o Programa Alfabetização Solidária, os efeitos da alfabetização vão além do resgate da autoestima, eles promovem o "resgate da dignidade" (Programa Alfabetização Solidária, 2000b, p.36), um aspecto encontrado com frequência no registro dos alunos: "foi o estudo [a alfabetização] que me tornou o que sou hoje uma pessoa digna e respeitada" [sic] (Escrevendo Juntos, 200 I, p.2).

De outra perspectiva analítica, os estudos de Alvarenga evidenciam que muitos discursos produzidos pelo Programa Alfabetização Solidária reforçam "ideias que foram transformadas em senso comum pela própria ideologia liberalburguesa" (Alvarenga, 2000, p. II). Um desses discursos mencionados pela autora é o do "analfabetismo como um mal do qual o analfabeto é portador, tendo na alfabetização a resposta para a cura" (p. I l). A autora exemplifica isso utilizando a carta de um aluno divulgada por uma das publicações do Programa, cujo excerto enuncia: "agora sei escrever discobrir algumas palavrinhas. Antes desta escola eu mim conciderava um cego. Valeu por tudo por colocar o enteresso da gente de sair da escuridão. Eu mim orgulho de escrevi meu nome" [sic] (Boletim do Programa Alfabetização Solidária, 1999a, p.2).

Alguns alfabetizadores e coordenadores do Programa reforçam a relação entre analfabetismo e doença. Em um dos artigos da publicação destinada aos alfabetizadores, a alfabetização passa a ser considerada a alternativa para "romper com o isolamento social do analfabeto, possibilitando-lhe as necessárias luzes da escrita e da leitura" (Barbosa, Neto, 200 I, p.38). Já em outra publicação, atribui-se à alfabetização a missão redentora de livrar o país do "quadro endêmico do analfabetismo" e de promover seu progresso e desenvolvimento (Boletim Alfabetização Solidária, 1999b, p.2), fortalecendo o "mito do alfabetismo", conforme denomina Graff (1990).

O resgate da autoestima é uma estratégia considerada importante pelo 
Programa para corrigir os problemas, os males, a "cegueira" provocada pelo analfabetismo, tanto em cada indivíduo quanto na sua comunidade. O fortalecimento da autoestima não deixa de ser tratado como instrumento para corrigir o olhar, conforme declarou um indivíduo alfabetizado pelo PAS no município de Codó, no Maranhão, em uma reportagem realizada por um jornal televisivo em 9/9/02. Antes de ingressar no Programa, ele sentia-se "um cego de vista limpa".

A crença na alfabetização como solução para atingir a "sanidade" social é encontrada também nas declarações dos empresários parceiros do Programa. No seu estudo, Alvarenga (2000) menciona um dos registros encontrados nas publicações do Programa de um de seus empresários patrocinadores: "Fiquei impressionado com o desejo de todos querendo aprender a ler e escrever. O simples fato de trabalharem durante o dia e frequentarem escolas à noite, demonstra o desejo de progredir" (Boletim Alfabetização Solidária, 1999a, p.8). A pesquisadora chama atenção para os sentidos atribuídos ao termo "desejo": "desejo de aprender a ler e escrever"; "desejo de progredir". São sentidos "que ilustram a mais perfeita explicação ideológica que preside o pensamento liberal-burguês, desde as suas origens" (p. |2).

Os registros do Programa demonstram não haver ruptura entre a racionalidade liberal-burguesa e a racionalidade neoliberal, como evidencia Alvarenga (2000). Nessas racionalidades, há o fortalecimento de um discurso ainda recorrente: o analfabetismo não é efeito das condições históricas produtoras das desiguais condições de vida que emergiram dos modelos socioeconômicos vigentes no decorrer dos tempos.

Como ressalta Rudiger ( 1996), os problemas enfrentados pelas pessoas (falta de oportunidade de trabalho, por exemplo), no global e flexível mundo contemporâneo, são atribuídos à condição própria do indivíduo. Nesse mesmo raciocínio, parece que "deixar de ser analfabeto, só dependerá única e exclusivamente de sua heroica vontade individual” (Alvarenga, 2000, p. I2). A força de vontade, a persistência, o esforço, a alegria, a esperança, a afetividade e a própria autoestima parecem ser capacidades pessoais, subjetivas e movidas pelos indivíduos quando bem desejam.

A autoestima, os relacionamentos, as personalidades, enfim, as subjetividades têm sido estudadas, desde épocas passadas, "em termos de estados internos que elas expressam" (Rose, 1998, p.30). No entanto, a "administração do eu contemporâneo" passa a considerar que as capacidades subjetivas e 
pessoais não estão apenas relacionadas ao "invisível mundo interior". Em vez disso, "a subjetividade faz parte dos cálculos das forças políticas no que diz respeito ao Estado-nação, às possibilidades e aos problemas enfrentados pelo país, às prioridades e às políticas" (Rose, 1998, p.31).

\section{CONSIDERAÇÕES FINAIS}

Neste texto, procurei mostrar que a ênfase na elevação da autoestima constitui uma estratégia para agir sobre os indivíduos analfabetos, mobilizandoos a ingressar no Programa Alfabetização Solidária e a permanecer nele, a fim de mudar suas condutas ao tornarem-se alfabetizados. Agindo sobre as ações dos alfabetizandos, mediante o aumento da autoestima, tanto eles próprios quanto o Programa procuram atingir estes objetivo: alfabetizar-se e diminuir os níveis de analfabetismo no país.

As ações estratégicas operam por meio de um conjunto de práticas, dentre as quais, três foram aqui esmiuçadas: a configuração da autoestima como um obstáculo à aprendizagem da leitura e escrita; o disciplinamento de corpos e mentes dos alfabetizandos para torná-los autoconfiantes; e a produtividade em investir nas capacidades subjetivas dos alfabetizandos e alfabetizadores. As capacidades subjetivas dos indivíduos envolvidos com o Programa Alfabetização Solidária não são apenas aspectos de sua vida privada - elas são controladas e dirigidas para alcançar as metas desejadas, que, em última instância, se traduzem no aumento dos índices de alfabetização do país.

A autoestima, antes de ser uma questão individual e privada, é uma estratégia de atuação. Considerada assim, a autoestima "não é concebida no nível da ideologia; nem é uma armadilha, uma panaceia, uma conspiração"; ao invés disso, "é uma forma de governar" (Cruikshank, 1996, p.238).

A forma estratégica da autoestima não funciona impondo os objetivos/ metas a serem alcançados; ao contrário, age seduzindo e incitando os analfabetos a acreditarem que procuraram se alfabetizar por sua própria iniciativa e vontade. Deixar de ser analfabeto passa a ser considerado como opção livre e autônoma do indivíduo, que procura se alfabetizar para seu próprio bem e o bem de toda a sociedade brasileira. Nisso reside o potencial da autoestima como estratégia para atingir os fins propostos: fazer da erradicação do analfabetismo, meta do Programa, um objetivo do próprio alfabetizando, disciplina- 
damente perseguido por ele.

Finalizando a discussão, novamente ressalto que reconheço a necessidade de considerar, por um lado, o desenvolvimento da autoconfiança dos alfabetizandos, em suas capacidades para alterar as condições sociais e econômicas dos contextos vividos. Por outro lado, também é preciso construir outros discursos e práticas (considerando que as práticas são inteligíveis pelos discursos), evitando fortalecer a culpabilização do analfabeto pela sua condição.

Advogo no sentido de inventar outras estratégias de governamento para lutar contra aquelas práticas cristalizadas. Tais práticas parecem desejosas de nos convencer de que os problemas dos indivíduos pouco estão relacionados com condições sociais, institucionais ou epistemológicas e de que eles têm "problemas porque são carentes de motivação, autoestima, autodisciplina, etc.", como nos advertia Popkewitz (200 I , p.73, grifo do autor), ao analisar como um programa engendrado por uma política pública americana administrava a "alma" dos sujeitos nela envolvidos.

\section{REFERÊNCIAS BIBLIOGRÁFICAS}

ALFABETIZAÇÃO SOLIDÁRIA. Reescrevendo a história de milhões de brasileiros. Disponível em: http://www.alfabetizacao.org.br/pt/participe/faq.asp. Acesso em: 10 fev. 2007.

ALVARENGA, M. S. Da cegueira à orfandade: a questão da cidadania nas políticas de alfabetização de jovens e adultos. In: REUNIĨO ANUAL DA ANPED, 23. Caxambu, 2000. (CD ROM. GT 6: Educação Popular)

ANDRÉ, C. M.; GODOY, K. M. A. Uma experiência em processo: alfabetização e Artes. Revista do Programa Alfabetização Solidária. São Paulo, v. I, n. I, p.9-18, jul./dez. 200 I .

BARBOSA, M. L. V.; NETO, J. M. A Unopar nos caminhos da alfabetização. Revista do Programa Alfabetização Solidária. São Paulo, v. I , n. I, p.29-40, jul./dez. 200 I.

BOLETIM ALFABETIZAÇÃO SOLIDÁRIA. Brasília, n. I, jul. 1997

n.4, mar. 1998

n.5, maio 1998a.

n.7, jan.ffev. 1999.

n.9, maio/jul. 1999a. 
. n. 10, dez. 1999b.

n. I I, jan./fev. 2000.

BUJES, M. I. E. Infância e maquinarias. Rio de Janeiro: DP\&A, 2002.

CORAZZA, S. M. O Que quer um currículo? Pesquisas pós-críticas em educação. Petrópolis: Vozes, 200 I, p. 97-I 27.

CRUIKSHANK, B. Revolutions within: self-government and self-esteem. In: BARRI, A.; OSBORNE, T.; ROSE, N. (eds.) Foucault and political reason: liberalism, neo-liberalism and rationalities of government. Chicago: The University of Chicago Press, 1996. p.23I- 251 .

ESCREVENDO JUNTOS. Brasília, n. 18 , set./out. 2001.

FISCHER, R. M. B. Foucault e a análise do discurso em educação. Cadernos de Pesquisa. São Paulo, n. II4, p. 197-223, nov. 2001.

A Paixão de trabalhar com Foucault. In: COSTA, M. V. (org.) Caminhos investigativos: novos olhares na pesquisa em educação. 2. ed. Porto Alegre: Mediação, 2002. p.37-60. FOUCAULT, M. A Ordem do discurso. 4. ed. São Paulo: Loyola, 1998.

O Sujeito e o poder. In. DREYFUS, H.; RABINOW, P. Michel Foucault, uma trajetória filosófica: para além do estruturalismo e da hermenêutica. Rio de Janeiro: Forense Universitária, 1995. p. 231-249.

Verdade e subjetividade. Revista de Comunicação e Linguagens, Lisboa, n. 19, p.203-223, 1993.

GRAFF, H. J. O Mito do alfabetismo. Teoria \& Educação, Porto Alegre, n.2, p.30-64, 1990.

KLEIN, L. et al. Programa Alfabetização Solidária: perfil dos alunos, impacto em 23 municípios do projeto piloto, avaliação do módulo 7. Brasília: PAS, 2000. (Avaliando, I).

KLEIN, M. Tecnologias de governamento na formação profissional dos surdos. Porto Alegre, 2003. Tese (dout.). Universidade Federal do Rio Grande do Sul.

POPKEWITZ. T. Lutando em defesa da alma: a política do ensino e a construção do professor. Porto Alegre: Artmed, $200 \mathrm{I}$.

PROGRAMA ALFABETIZAÇÃO SOLIDÁRIA. Avaliação: grandes centros urbanos (módulo 8). Brasília, 2000.

Escrevendo as páginas do futuro: relatório de 4 anos de atividade do Programa Alfabetização Solidária: janeiro de 1997 a dezembro de 2000. Brasília, 2001. 
Mil dias reescrevendo o Brasil: relatório de três anos de atividade do Programa Alfabetização Solidária: janeiro de 1997 a dezembro de 1999. Brasília, 2000a.

Terceiro concurso de redação do Programa Alfabetização Solidária. Brasília, 2000b.

ROSE. N. Governando a alma: a formação do eu privado. In. SILVA, T. T. (org) Liberdades reguladas: a pedagogia construtivista e outras formas de governo do eu. Petrópolis: Vozes, 1998. p.20-45.

RUDIGER, F. R. Literatura de autoajuda e individualismo: contribuições ao estudo da subjetividade na cultura de massa contemporânea. Porto Alegre: Ed. UFRGS, 1996.

SILVA, J. S. Representações sociais da escola noturna: uma construção psicossocial do espaço escolar. Teresina, 2003. Tese (mestr.) Universidade Federal do Piauí.

SILVA, T. T. Pedagogia e autoajuda: o que a sua autoestima tem a ver com o poder? In: SCHMIDT, S. (org). A Educação em tempos de globalização. Rio de Janeiro: DP\&A, 200 I . p.40-44.

TAVARES, M. R. Autoestima: o que pensam os professores? São Paulo: 2002. Tese (dout.) Pontifícia Universsidade Católica de São Paulo.

TERZI, S. B. A Experiência em Inhapi e Olho d'Água do Casado, AL. Revista do Programa Alfabetização Solidária. São Paulo, v. I, n. I , p. I43- I53, jul./dez. 200 I.

VEIGA-NETO, A. Coisas do governo... In: RAGO, M.; ORLANDI, L. B. L.; VEIGA-NETO, A. (orgs.) Imagens de Foucault e Deleuze: ressonâncias nietzscheanas. Rio de Janeiro: DP\&A, 2002. p. 13-34.

Educação e governamentalidade no neoliberalismo: novos dispositivos, novas subjetividades. In: PORTOCARRERO, V.; BRANCO, G. C. (orgs.) Retratos de Foucault. Rio de Janeiro: Nau, 2000. p. $179-217$.

Recebido em: março 2007

Aprovado para publicação em: março 2009 